International Review of Research in Open and Distributed Learning Volume 21, Number 2

April - 2020

\title{
Sprinting to the Finish Line: The Benefits and Challenges of Book Sprints in OER Faculty-Graduate Student Collaborations
}

Gabriela C. Zapata

Texas A\&M University

\begin{abstract}
This article investigates the results of a book sprint experience whose main objective was the development of instructional modules for an open textbook for the teaching of Spanish as a second language. Six graduate students at a public American university participated in the project for a week, working in pairs in the creation of activities that required the incorporation of the tenets of the dual pedagogical frameworks of performance- and literacy-based instruction (as realized through learning by design). Data were collected through both an opinion survey and the assessment of samples of the participants' products. The results of the survey showed that graduate students felt that being part of the book sprint had been beneficial both at the professional and personal levels, but they had also experienced difficulties similar to those reported in previous studies. The products analyzed pointed to a lack of connection between the required pedagogical tenets and the materials developed, which has also been reported in existing works on pre- and in-service teachers as materials developers. The article discusses how these results could have been a consequence of the structure of the book sprint, and it offers recommendations for future activities of this kind.
\end{abstract}

Keywords: book sprints, open education, OER materials, second language pedagogy, graduate student professionalization 


\section{Introduction}

Two of the most important developments that the field of second language (L2) pedagogy has seen in the last 10 years have been the adoption of performance- and literacy-based instructional approaches (Allen \& Paesani, 2010; American Council on the Teaching of Foreign Languages [ACTFL], 2012; Warner \& Dupuy, 2018) and the increasing interest in open educational resources (OER; Blyth, 2014). The establishment and growth of two non-profit academic organizations-such as the Center for Educational Resources in Culture, Language and Literacy (CERCLL) and the Centre for Open Educational Resources \& Language Learning (COERLL) - attest to these trends. These movements originate in the compelling need to prepare students to understand and actively use their second languages in the production of the kinds of texts common in today's diverse, multimodal world, and also to offer them personalized, affordable, educational materials, which commercial, one-size-fits-all L2 textbooks cannot do (Blyth, 2014; Thoms \& Thoms, 2014). That is, OER-based L2 instruction can facilitate the implementation of instruction that answers learners' personal and academic needs, and that can open L2 use to the dearth of genres that characterizes today's world of communication.

However, in spite of these trends and the resources that both CERCLL and COERLL have offered educators, one problem persists: the availability of open, theoretically grounded L2 instructional resources (Thoms \& Thoms, 2014). This was the case for Spanish before the start of the experience presented in this article, a missing resource that inspired a learning materials development project that would result in, to the best of the author's knowledge, the first open textbook for beginning L2 Spanish for university students in the United States. The creative process was carried out by a faculty member and six graduate students in a public university in the southern region of the United States. Throughout a period of one week, they worked together in a book sprint to develop the four instructional chapters that would become part of the first volume of the textbook.

Our first objective was to describe this experience, and to explore the participating graduate students' perceptions of the process in order to discover the possible benefits of this kind of activity for their professionalization. Our second goal was to analyze the products created by the students to investigate whether they reflected the tenets of the two pedagogical frameworks (performance-based instruction and learning by design) in which the content was required to be grounded. To the best of theauthor's knowledge, no existing work has looked at the use of book sprints for L2 materials development, nor has it analyzed their potential for graduate education. ${ }^{1}$

The article is organized as follows. The first section of the paper provides a definition of book sprint as it is understood in the OER world and presents previous studies. The next four sections describe the study: (a) the institutional background, and structure of and rationale behind the book sprint; (b) the participants; (c) the materials; and (d) the protocols. The subsequent two sections present the results of the study and discuss their limitations and implications. A final brief section concludes. 


\section{Previous Book Sprint Experiences}

The idea of book sprints for the development of OER materials was first put forward by Tomas Krag and his team in 2005 (Kean, 2012). Book sprints can be defined as creative, collaborative "process[es] [that] start with a group of five-ten people, a facilitator, and an idea or title for a book, and wrap up five days later, culminating in the production of a finished book" (Hyde, 2010, p. 241). Those who participate in book sprints share a common expertise and resort to digital platforms (e.g., Google docs) to collaborate during the writing activity. Also, when needed, they incorporate existing open resources to develop novel material that is always published digitally, and is made available under one of the Creative Commons licenses. Book sprints are quite common in non-academic contexts for the development of software, apps, and manuals (see Kean, 2012; Zennaro, Canessa, Fonda, Belcher, \& Flickenger, 2007). In education, to the best of the author's knowledge, there have been three reported book sprint experiences, and their objective, as expected, has been the development of textbooks or monographs for different disciplines.

Thayer (2012) made reference to the first one: an initiative that took place in late summer 2012, in Finland, where a high school math textbook was produced during a weekend by a collaborative group of researchers, instructors, and students. The resulting product was a 130-page digital book with an open CC-BY license. Since the publication of the first textbook, the Finnish group has continued collaborating, and they have produced books for other math-related topics such as calculus. Unfortunately, neither Thayer nor the group (in the Facebook site devoted to the project) provided any information about the number of people that participated in the effort, nor did they discuss students' roles or how they benefitted from the experience of co-writing the textbook with faculty and researchers.

The setting for the second academic book sprint in the existing literature was the University of British Columbia in Canada, where, in 2014, a group of faculty experts in the field of geography gathered to produce a university-level textbook on geographical aspects of British Columbia (Green, 2016). This time, the production period took place over four days, but the writers worked in 12- to 14-hour cycles. The collaborative effort resulted in a 200-page open textbook that was subsequently peer-reviewed, edited, and published by the university's faculty and IT staff. Even though this experience was mostly successful, Green (2016) also described some challenges. For example, he believed that, before the start of the writing process, it is important to allot time for collecting and organizing resources to fully devote the book sprint time to writing and not research. In addition, he reported the existence of difficulties with the division of labor due to the different levels of participation displayed by the writers, and, thus, he recommended the establishment of preliminary meetings to discuss issues of accountability. In spite of the reported challenges, this researcher believed this kind of writing experience is worthwhile because it "can create a first draft and open us to potential, because all open textbooks really are first drafts waiting for improvement" (Green, 2016, p. 189).

Taylor (2016) reported on the third academic book sprint in the literature. This time, the collaborative writing experience involved the participation of 10 experts in the field of modern languages, with a focus on the digital humanities and literature, who wrote 24 individual blogs that explored different aspects of digital scholarship in that discipline. The book sprint took place during one week in November 2015, and it was organized by two faculty members at the University of Liverpool, who developed both the main topic to be addressed by the writers and six questions that also needed to be incorporated into their work. The experts' 
writing resulted in a 13,000-word piece, published in a digital platform. Even though Taylor deemed this experience successful, like Green (2016), she also makes reference to some challenges. For example, it was hard for the authors to write in the same style and with a common authorial voice. Also, the contributors felt time pressure due to, she believed, the fact that "the timescale was certainly different from that experienced by most academics when writing an academic piece" (Taylor, 2016, p. 29). Taylor suggested that the challenging issues the participants encountered could be addressed by careful planning and monitoring of the writing activity as it unfolded. Despite the reported negative aspects, this book sprint resulted in the fruitful collaboration of experts in various parts of the world.

These three projects for print-based academic books have provided us with information about the necessary conditions to achieve successful results. In addition, they have clearly pointed to the value of collaboration through this type of writing activity. However, only one of them (Thayer, 2012) included student participation, and no data were provided about either the number of participants, or the way in which they participated, or how they benefitted from the experience. Also, the three reports failed to include any specific instruments to collect evidence. This paper seeks to contribute to the research on book sprints by not only providing more information about the implementation of this type of activity at an American university, but also filling the existing gaps by exploring its effects on graduate student professionalization, as well as examining the resulting products in more depth than in previous studies.

\section{The Study}

\section{Research Questions}

This work describes a book sprint experience in an American university with graduate student participation. In addition, it attempts to provide comprehensive answers to the following questions:

1. What professional and personal benefits do the graduate students who participated in the book sprint report after finalizing their writing activity?

2. How do the resulting products reflect the tenets of performance-based instruction and learning by design?

In the next sections, we provide information about the institutional background of which the book sprint was part and the process itself. Then we present information on the participants, instruments, and methods of data collection and analysis that were employed to answer the research questions.

\section{Institutional and Project Background}

The book sprint project took place for a week in early August 2018 at a public university in the southern region of the United States. Theimpetus behind it was the need to develop an OER textbook for the teaching of beginning Spanish that would provide the students at the institution not only with an affordable instructional option, but also with a solid, theoretically-based product, which could not be accomplished with a commercial, one-size-fits-all L2 textbook. The goal was to create an instructional tool that would be 
connected to the personal and academic experiences of the students at the institution, would increase their understanding of Spanish oral and written texts, and would facilitate the use of their L2 for communication in different social contexts (what is defined as performance-based instruction; ACTFL, 2012). Also, in accordance with a literacy-based focus, the new resources would allow learners to understand the relationship between linguistic structures and meaning as presented in diverse types of texts. To achieve these goals, students would be working within the knowledge processes (experiencing, conceptualizing, analyzing, and applying) in the literacy-based framework known as learning by design. This would facilitate "the reciprocal connection between . . . academic learning (conceptual scheme, critical analysis, etc.) and [the] grounded, real-world practical experiences and applications, or simulations of these [that characterize performance-based instruction]" (Cope \& Kalantzis, 2015, p. 16).

Even though at the time when the book sprint was planned there were a few, unrelated OER activities for beginning Spanish available digitally (e.g., Zapata, 2017), there was not an open, complete curricular option that reflected the tenets of performance- and literacy-based instruction. Therefore, there was a need for new material. In addition, the book sprint would offer graduate students at the institution the opportunity to grow both as L2 teachers and as materials developers by synthesizing and combining the pedagogical knowledge they had acquired in their recent methods class and the experience they had accumulated through their practice.

The person in charge of both the textbook initiative and the book sprint was a faculty member who was not only a specialist in L2 acquisition and pedagogy, but also the Spanish Basic Program director. She had also taught the graduate methods class, in which the pedagogical bases of the pending OER textbook had been included. Due to the lack of major funding for the OER book, she felt the best alternative for its development (or at least for its first draft) was a book sprint.

The book sprint alternative was viable for several reasons. First, this activity was financially feasible because she could secure small stipends for the participating graduate students, and she had free access to the institution's resources (e.g., a computer room where it could be carried out). Second, the book sprint would allow graduate students to work with their peers to complete the writing process collaboratively. Third, the book sprint would broaden their knowledge of different aspects of open educational resources (e.g., their origin, Creative Common licenses). Fourth, it would strengthen their existing conceptualizations of performance- and literacy-based instruction (as grounded in learning by design). And finally, it would contribute to their overall professional training.

The faculty member in charge first organized the logistics of the book sprint based on the experiences of others, so she followed the recommendations outlined by Banfield, Lombardo, \& Wax (2016) and Kean (2012). For example, she secured a comfortable, quiet room with the resources that would allow the team to work together, as well as stipends for the graduate students. Also, as recommended in the literature, she developed a methodology (Taylor, 2016) that she and the graduate student collaborators would follow, setting specific rules for the whole activity (e.g., time frames, collaboration). The next step involved determining the time frame. The second week of August was deemed appropriate because students were back from their summer breaks, and orientations and classes had not started yet. The writers would meet for seven hours every day from Monday to Friday and would write in a common space. 
Since the main goal of the book sprint was to finish the first volume of the textbook, which was to include an introductory module (already written) and four other ones, the faculty member in charge felt that six graduate student participants would be ideal. That is, she would be in charge of the first chapter, and the students, working in pairs, would write the subsequent three. Once this person had secured funding for stipends, she sent an invitation for participation to all graduate students in her department, stating that in order to participate in the project, they not only had to have had at least one year of teaching experience, but they also had to have taken the methods class. The main reason behind these requirements was the fact that the book was grounded in specific pedagogical frameworks, and in order to quickly create activities that would reflect the necessary theoretical tenets, collaborators needed to have solid, previous knowledge of those tenets. Also, since the textbook was going to answer the specific personal and academic needs of the students belonging to the institution, it was crucial for the writers to know what these learners were like (e.g., topics they were interested in, cultural and social background), which was why the participants had to have taught for at least one year at the institution.

In order to avoid the problems reported in previous studies (e.g., Green, 2016), the faculty member established clear rules for participation (e.g., the division of labor within and among pairs) and the following outcomes:

1. By the end of the fifth day, all pairs will have produced and edited their chapter, and will have organized the additional materials (e.g., photos and citation information) in the Google folders provided.

2. The chapters developed by each pair will reflect the tenets of performance-based instruction (as detailed in ACTFL, 2012) and learning by design (as detailed in Cope \& Kalantzis, 2015).

Also, before the start of the activity, the faculty member in charge created Google folders for each team, in which she placed both the introductory module she had written previously (this document would act as the example to be followed) and resources (e.g., photos, videos, links to Websites) that could be used in the chapters. In addition, she organized the work pairs based on the students' personalities and relationships (e.g., she considered whether they got along, whether they were friends). Three days before the start of the book sprint, she sent all the collaborators a reminder, and she shared the project's Google folders with them.

The first two hours of the first day of the sprint were devoted to presenting the project and the book sprint itself. The faculty member in charge talked about the objectives of the OER initiative, the pedagogical frameworks in which it was grounded, and the characteristics of book sprints in general. She also provided graduate students with information about OER licenses, pointing out what could and could not be included in the materials. Finally, she discussed the rules that each pair needed to follow, as well as the outcomes she had set for that particular group's work. The writing process started immediately after this presentation. Even though specific procedures had been established for the pairs, the participants were also given the freedom to approach the task in the way they deemed most convenient. The rest of that first meeting and the days that followed proceeded in the same way. The group worked together for three hours in the morning, stopped for one hour to have lunch and relax, and continued their work for another three hours in the afternoon. By the end of the week, all the products were uploaded to the Google folder for the activity, and the graduate student collaborators completed an online, open survey that probed their opinions of the 
experience. The resulting chapters were edited by the faculty member in charge throughout the fall 2018 semester, and they are now available as the published first volume of the textbook.

\section{Participants}

The participants in this study were six graduate students (one male, five females), who were part of a doctoral program with concentrations in Hispanic literature, cultural studies, and linguistics at an American, public university. Their average age was 34 years old. Five participants were native Spanish speakers, and one of them was a native English speaker. All of them had at least one year of experience teaching Spanish at that institution, and had received training in the pedagogical frameworks in which the OER textbook was grounded-performance-based instruction and learning by design. All of them had volunteered for the project, though they received a small stipend for their participation.

The participants were organized in three working pairs to facilitate and enhance the creative process, and each pair was given a number (1,2, or 3). Each pair consisted of a graduatestudent who was in thelinguistics concentration of the doctoral program, and one that was in literature. The members of pair \#1 were in their mid-twenties and had at least three years of teaching experience. The students in pair \#2 were older (in their thirties and early forties) and they had at least five years of teaching experience. Pair \#3 was similar in age to pair \#2, but the participants had differing levels of experience-while one of them had at least five years of experience, the other had only one year. The members of the three pairs had worked with the faculty member in charge as graduate teaching assistants in the Spanish program she directed. They had also been her students in the methods class.

\section{Instruments}

Data for this study were collected in two ways. The first source of data was a survey with 10 open-ended questions (Appendix) that probed the participants' perceptions of the book sprint experience and was distributed via Google Forms once all work had been finalized. The second source of data were the products developed by the participants. Samples of the content they produced were analyzed by the researcher in order to investigate whether they reflected the tenets of the pedagogical frameworks in which the textbook was expected to be grounded.

\section{Procedures}

The opinions that the participants expressed in the survey were analyzed qualitatively. In the first step, categorical aggregation, the researcher read the participants' responses to the 10 questions in the questionnaire to identify themes. Then, she coded each emerging theme and developed a list of categories and exemplifying statements for each of them. In the next step, she cross-examined themes, categories, and statements, applying Glaser's (1965) constant comparative method of data analysis to ensure that there were no discrepancies in the initial analysis.

In order to discover if the products developed by the graduate student collaborators reflected the tenets of both performance-based instruction and learning by design, the researcher assessed two sections representative of two of the three main module components, namely communication (presentation of vocabulary) and language (presentation of a grammar structure). ${ }^{2}$ She focused on the presence or absence of the frameworks' main principles and expected instructional elements. These were organized into a total 
of nine categories (Table 1). If these categories were present in all activities in the section analyzed, the category received two points; if they were partially present, the category received one point; and if they were absent, no points were allotted. The total possible points for each section was 18, and for the two, 36. In addition, the quality of the resources used was evaluated. If the two parts that were analyzed incorporated high-quality photos and/ or videos and the preferred licenses in the project (i.e., CC, CC-BY, and CC-BY SA), they were given two points. This brought the total points that products could get to 38. The numerical results of this assessment were analyzed using descriptive statistics.

Table 1

Categories Used for Analysis of Products

\begin{tabular}{|c|c|}
\hline Performance-based instruction & Learning by design \\
\hline $\begin{array}{l}\text { 1. Activities promote authentic, real world use } \\
\text { of language, even though the language is } \\
\text { learned and practiced in a learning } \\
\text { environment. }\end{array}$ & $\begin{array}{l}\text { 4. Reflects the principle of belonging; content } \\
\text { (topics and activities) has a direct relation } \\
\text { with students' lifeworld and informal } \\
\text { learning. }\end{array}$ \\
\hline \multirow{7}{*}{$\begin{array}{l}\text { 2. Variety of tasks related to the curriculum. } \\
\text { 3. Language is presented in meaningful } \\
\text { communicative contexts. }^{\text {a }}\end{array}$} & 5. Resources used are authentic and \\
\hline & multimodal. \\
\hline & Knowledge processes reflected in content: \\
\hline & 6. experiencing the known and the new; \\
\hline & 7. conceptualizing by naming and with theory; \\
\hline & 8. analyzing functionally and critically; and \\
\hline & 9. applying appropriately and creatively. ${ }^{\mathrm{b}}$ \\
\hline
\end{tabular}

*Note. aAdapted from ACTFL Performance Descriptors for Language Learners (p. 4), by American Council on the Teaching of Foreign Languages, 2012, Alexandria, VA: ACTFL. Copyright 2012 by ACTFL.

bAdapted from "The Things You Do to Know: An Introduction to the Pedagogy of Multiliteracies," by B. Cope and M. Kalantzis, in B. Cope and M. Kalantzis (Eds.), A Pedagogy of Multiliteracies: Learning by Design (p. 4), 2015, London, UK: Palgrave Macmillan. Copyright 2015 by Bill Cope and Mary Kalantzis.

\section{Results}

\section{Research Question 1: Professional and Personal Benefits Reported by the Graduate Students}

All graduate students participating in the book sprint seemed to have had positive opinions of the experience. The main professional benefits reported were connected to the following opportunities: (a) learning more about open education, OER materials, and licenses; (b) reviewing and practically applying the concepts they had learned in their methods class; and (c) becoming co-authors of a beginning Spanish textbook, which would enhance their curriculum vitae (CV). The writers also felt that the need to develop activities that students would use in a classroom had given them a new outlook on their teaching practice. Additionally, three of the six participants believed that working with a partner with a different perspective on instruction had complemented and enhanced their knowledge of possible pedagogical moves that could be integrated into their practice. 
When discussing the personal benefits of the experience, all participants made reference to the collaborative nature of the work, which not only had allowed them to complete a task that they would not have been able to achieve on their own, but had also brought them closer to both their pair partner and the rest of the collaborative team. Furthermore, two of the collaborators felt that being part of the book sprint had made them feel more confident about their abilities as both teachers and materials developers. These two students were among the less experienced of the overall group. In addition, two other members of the group believed that collaboration had resulted in their becoming better communicators and collaborators. The themes present in the participants' opinions and representative quotes are summarized in Table 2.

Table 2

Student-Reported Benefits of Book Sprints

\begin{tabular}{|c|c|}
\hline Themes & Representative statements \\
\hline $\begin{array}{l}\text { Being able to learn more } \\
\text { about open education, } \\
\text { OER, and materials } \\
\text { development }\end{array}$ & $\begin{array}{l}\text { "The OER/ copyright information that I learned will help me with my } \\
\text { professional future. Also, the experience of writing a textbook (explaining, } \\
\text { grammar concepts, creating engaging activities, finding authentic OER } \\
\text { resources) is very helpful." }\end{array}$ \\
\hline $\begin{array}{l}\text { Reviewing and applying } \\
\text { theoretical concepts }\end{array}$ & $\begin{array}{l}\text { "There are too good things [sic] to say about this experience, for example, } \\
\text { it give [sic] us (graduate students) the opportunity to review and apply } \\
\text { what we have been learning about pedagogy (hands on)." }\end{array}$ \\
\hline Becoming a co-author & $\begin{array}{l}\text { "It gave us the opportunity to be co-authors. This will help our CV, to get a } \\
\text { job..." }\end{array}$ \\
\hline $\begin{array}{l}\text { Contributed to } \\
\text { enhancement of own } \\
\text { teaching practice }\end{array}$ & $\begin{array}{l}\text { "It is an experience that allows you to think about your personal teaching } \\
\text { style: how you explain concepts, how you relate to your students, how you } \\
\text { scaffold activities, how you maintain students' interest. More importantly, } \\
\text { book sprints allow you to learn from others through the exchange of ideas." }\end{array}$ \\
\hline Collaboration & $\begin{array}{l}\text { "Work team collaboration for me was the most positive experience. I was } \\
\text { able to work with freedom, but, at the same time, my partner was an } \\
\text { important factor to clear my ideas and keep [my work] on track." }\end{array}$ \\
\hline $\begin{array}{l}\text { Contributed to the } \\
\text { enhancement of } \\
\text { confidence as } \\
\text { teacher/materials } \\
\text { development }\end{array}$ & $\begin{array}{l}\text { "I think that this experience made me feel worth and confident about doing } \\
\text { what I love, teaching, and the process of creating material in a friendly } \\
\text { environment." }\end{array}$ \\
\hline $\begin{array}{l}\text { Contributed to the } \\
\text { development of } \\
\text { communication and } \\
\text { collaboration skills }\end{array}$ & $\begin{array}{l}\text { "On a personal level, I learned how to better communicate and collaborate } \\
\text { with others in a professional setting." }\end{array}$ \\
\hline
\end{tabular}




\section{Research Question 2: Products That Reflected the Tenets of Performance-Based Instruction and Learning by Design}

By the end of the book sprint week, none of the collaborative pairs had been able to finish the modules they had been assigned. Only one pair had approached completion, but several elements were still missing from their work. When the activities in the two sections were analyzed using the categories that referred to the principles and instructional elements of both performance-based instruction and learning by design, it was clear that none of the graduate student pairs had fully incorporated them into their work. However, there were similarities and differences among the resulting products. For example, the learning by design principle of belonging and the experiencing knowledge process were reflected in all the pairs' work, since the resources that they had developed were closely connected to students' lifeworld and interests. However, the presence of the other elements in the participants' work varied. The results of the assessment are summarized in Table 3.

Table 3

Results of Product Assessment

\begin{tabular}{lccccc}
\hline Categories & Total for pair \#1 & Total for pair \#2 & Total for pair \#3 & M & SD \\
\hline $\begin{array}{l}\text { Points for vocabulary } \\
\text { section } \\
\text { (communication) }\end{array}$ & $8 / 18$ & $17 / 18$ & $4 / 18$ & 9.67 & 6.66 \\
$\begin{array}{l}\text { Points for grammar } \\
\text { section } \\
\text { (language) }\end{array}$ & $8 / 18$ & $13 / 18$ & $12 / 18$ & 11 & 2.65 \\
$\begin{array}{l}\text { Points for quality of } \\
\text { resources }\end{array}$ & $2 / 2$ & & & & \\
\hline
\end{tabular}

The vocabulary section exhibited the highest number of differences among the three pairs, as is reflected in the standard deviation number in Table 3. Only the product developed by pair \#2 (the most experienced teachers) incorporated almost all of the required elements, receiving 17 points out of the possible 18. Not only did these graduate students present the focal words in a textual context, but they also created activities that promoted authentic use of the language, and they incorporated multimodal resources to do so, which, overall, reflected the goals and tenets of performance- and literacy-based instruction (as represented by learning by design). In contrast, pair \#1 failed to include most of the required elements. For example, not only was there no textual context to introduce the vocabulary, but the majority of activities also consisted of discrete point exercises (e.g., drills, student interactions that would not promote active use of Spanish for communication), which were more connected to traditional L2 methodologies than to performancebased instruction and learning by design's knowledge processes. Pair \#3 also made limited use of authentic, multimodal resources, along with using visual elements that were of poor quality (e.g., not age-appropriate for university students, low-definition photographs). Finally, this pair did not follow the instructions given regarding Creative Commons licenses. The work produced by pair \#1 included more elements than did that 
of pair \#3, but it had similar problems such as the lack of vocabulary presentation in context and the absence (or partial presence) of activities incorporating learning by design's knowledge processes.

The assessment of the grammar section rendered similar results among the three pairs (Table 3). Pair \#2 had the highest number of points, but their work was not as effective as in the vocabulary section. For example, the activities they developed only partially reflected the tenets of either performance-based instruction or learning by design, and there was no clear connection between grammar rules and use. The work of pair \#3 included more of the required elements than in their vocabulary tasks (see above), but still only partially. Pair \#1 did not present grammar structures in communicative (i.e., textual) contexts, and they failed to incorporate activities in two of the four learning by design knowledge processes. The resources used by the three pairs were of better quality than those in the vocabulary sections, but they were neither multimodal nor authentic, except in the case of pair \#3, who resorted to an authentic video to provide a social context to present the featured grammatical structures.

\section{Discussion}

The opinions expressed by the graduate students in the survey suggest that the book sprint resulted in both professional and personal benefits for them. For example, through their participation in this experience, they were able to learn more not only about open education, Creative Commons licenses, and OER, but also about the process of materials development. In addition, the book sprint provided them with the opportunity to refresh and broaden their knowledge of the pedagogical frameworks they had learned in their methods class and had been incorporating in their practice, and was a way to enhance the professional development section of their CV. An indirect, professional benefit reported was the reflection on their own teaching that their work on the modules had brought about.

At the personal level, the main benefit of the book sprint, as in the case reported by Taylor (2016), seemed to have been the collaborative, collegial work environment. All graduate students reported the opportunity to work with their peers as the most important personal aspect of the experience, not only because it allowed them to get closer to their partners and the group as a whole, but also because it resulted in their own personal growth as both communicators and collaborators. The success of the collaborative context of the book sprint was clearly observed in the harmonious, yet heterogeneous, work environment that took place during that week. ${ }^{3}$ That is, unlike the book sprint experience described by Green (2016), in this one, there appeared to have been no friction among the collaborators.

The opinions expressed in the survey and the observation of the collaborative work environment suggest that the graduate students in the book sprint not only took the task at hand seriously, but also worked hard, following all therules provided for the division of labor. In addition, as both Green (2016) and Taylor (2016) recommended, they were provided with an outline of the topics to be included in their modules and an ample number of resources to incorporate into their work. However, in spite of these factors, none of the pairs was able to write a complete draft. The collaborators' failure to achieve the expectations and outcomes set up at the beginning of the book sprint could be due to a variety of reasons. 
For example, in the survey, all participants stated their frustration with the time period allotted to the project, since they felt that "a little bit more time would have resulted in better activities that would have reflected the methodology better" (participant \#5). Also, three of the collaborators complained that the open materials that had been given to them to include in their modules had been insufficient. These two complaints echo the problems reported by both Green (2016) and Taylor (2016).

These results suggest that, even though the faculty member in charge had tried her best to follow recommendations from previous studies and book sprint experts such as Banfield et al. (2016), there were still problems with this experience. Perhaps the six hours per day format was not enough for the development of activities for graduate students who, despite having teaching experience and being excellent teachers (as evinced by their high student evaluations and the program director's assessment), had never worked as independent materials developers before. Also, even though the collaborators in each pair had very good relationships with one another, they belonged to different doctoral concentrations and were not used to working collaboratively. This, in turn, might have resulted in differences in both the way they viewed and approached the task. Finally, these problems might have been exacerbated by the stress of having to find more open resources.

All these factors may also have contributed to the difficulties that the graduate students seemed to have had when they tried to materialize the tenets of both performance-based instruction and learning by design in their products. The results of the assessment of the sample vocabulary and grammar sections in the participants' modules suggest that they were not able to fully incorporate elements that reflected the required pedagogical tenets. Only the members of pair \#2 were almost able to fulfil the expectations set up at the beginning of the book sprint, which was probably connected to their joint teaching experience and the presence of a doctoral student whose main focus was L2 pedagogy. The materials developed by the other two pairs resembled more the kinds of activities found in the commercial textbook that they had been using in their classes. This appears to signal a disconnection between the participants' knowledge of performanceand literacy-based instruction and their ability to transfer it to the creation of materials. That is, it seems that the experience they had had teaching with commercial textbooks leaked into their work and influenced it more than what they had learned explicitly in their methods class about performance-based instruction and learning by design. This type of disconnect has been reported in theliterature on materials development by pre- and in-service instructors. For example, existing studies (e.g., Bouckaert 2018; Kuzborska, 2011) have shown that, when creating instructional materials, teachers often rely more on their prior teaching experiences, intuitions, and personal views of L2 learners and the learning process, rather than on their fields' theories, conceptualizations, and frameworks.

These results suggest that, even though the book sprint collaborators had teaching experience and knowledge of both performance- and literacy-based instruction (as framed in learning by design), they were perhaps still not ready to undertake materials development for a project such as a complex textbook. It is possible that a more effective course of action would have been to assign separate sections instead of whole modules to each pair, and tasks within specific knowledge processes instead of within all of them. These more realistic expectations and objectives could have resulted not only in a more comprehensive learning experience for the graduate students, but also in products that approached the expected outcomes more closely. 


\section{Limitations and Implications}

Even though the results of this study suggest that graduate students' participation in book sprints might result in personal and professional benefits, there are limitations to this work. First, the sources of data on the participants' perceptions of the experience are limited. The survey used in this work could have been complemented by interviews before and after the book sprint, which could have shed more light on expectations as well as individual benefits and challenges. As a result, a more comprehensive picture of the experience could have been achieved. Also, debriefings or think-aloud protocols with members of each pair could have offered more information on their creative process and choices, and this could have rendered a more in-depth understanding of the reasons why they had difficulties completing their task and materializing the expected pedagogical tenets.

The findings also suggest that book sprints need to be structured in a different way if graduate students are expected to be part of the process. First of all, it might be important to review the pedagogical and theoretical tenets expected to ground the materials before the beginning of the writing process. Perhaps, one or two theoretical sessions could be organized and connections between theory and practice could be made explicit through the analysis of existing samples. Additionally, the results appear to show that the participants might have felt overwhelmed by the responsibility of developing whole chapters in such a short period of time. Thus, it might be more feasible to limit work to instructional sections, instead of whole chapters. When considering the positive aspects of this experience, it seems that the clear rules and expectations set at the beginning of the activity for group work contributed to its collegial and productive environment. Clearly, as Taylor (2016) suggested, rules and expectations for the division of labor and collaboration are a must.

\section{Conclusion}

As open education continues to grow in L2 teaching, book sprints may offer valuable opportunities for the much-needed development of personalized, theoretically sound materials, as well as for collaboration and professional growth. Nevertheless, as shown in this work, it is important to consider collaborators' academic and personal needs. In the same way as L2 one-size-fit-all textbooks cannot answer specific student needs, a one-size-fits-all book sprint will not be effective for the development of materials. Careful planning, guidance, and personalization are essential for the success of this type of activity. 


\section{References}

Allen, H. W., \& Paesani, K. (2010). Exploring the feasibility of a pedagogy of multiliteracies in introductory foreign language courses. L2 J ournal, 2, 119- 142. https:// doi.org/ 10.5070/L2219064

American Council on the Teaching of Foreign Languages. (2012). ACTFL performance descriptors for language learners. Alexandria, VA: ACTFL. Retrieved from https:// www.actfl.org/ sites/ default/files/pdfs/ACTFLPerformance-Descriptors.pdf

Banfield, R., Lombardo, C. T., \&Wax, T. (2016). Design sprint: A practical guidebook for building great digital products. Sebastopol, CA: O’Reilly.

Blyth, C. (2014). Open educational resources and the new classroom ecology. The Modern Language J ournal, 98, 662- 664. Retrieved from https:/ / www.jstor.org/ stable/ 43649910

Bouckaert, M. (2018). Current perspectives on teachers as materials developers: Why, what, and how? RELCJ ournal, 50, 439-456. https:// doi.org/ 10.1177/0033688218810549

Cope, B., \& Kalantzis, M. (2015). The things you do to know: An introduction to the pedagogy of multiliteracies. In B. Cope \& M. Kalantzis (Eds.), A pedagogy of multiliteracies: Learning by design (pp. 1-36). London, UK: Palgrave Macmillan.

Glaser, B. G. (1965). The constant comparative method of qualitative analysis. Social Problems, 12(4), 436- 445. https:// doi.org/ 10.2307/ 798843

Green, A. G. (2016). Sprinting towards an open geography. In P. Blessinger \& T. J . Bliss (Eds.), Open education: International perspectives in higher education (pp. 186- 189). Cambridge, UK: Open Book Publishers. http:// dx.doi.org/ 10.11647/OBP.0103

Hyde, A. (2010). Book sprints and booki: Re-imagining how textbooks are produced. In R. T. Scholz (Ed.), Learning through digital media: Experiments in technology and pedagogy (pp. 241-247). New York, NY: The Institute for Distributed Creativity.

Kean, M. (2012). Open source publishing, 'book sprints' and possible futures. J unctures, 15, 27- 32. Retrieved from https:// www.researchgate.net/publication/293070452_Open_source_publishing_'book_sprints' and possible futures

Kuzborska, I. (2011). Teachers' decision-making processes when designing EAP reading materials in a Lithuanian university setting. J ournal of English for Academic Purposes, 10, 223- 37. https:// doi.org/ 10.1016/j.jeap.2011.07.003 
Rossomondo, A. (2012). The Acceso project and foreign language graduate student development. In $\mathrm{H}$. Allen \& H. Maxim (Eds.), Educating the future foreign language professoriate for the 21st century (pp. 128-148). Boston, MA: Heinle Cengage.

Taylor, C. (2016). Digital scholarship and writing sprints: An academic author perspective. Insights, 29(1), 26- 30. http:// dx.doi.org/ 10.1629/ uksg.286

Thayer, T. (2012). Book sprints: Fast track to rigorous open educational resources. Retrieved from http:/ / www.education4site.org/ blog/ 2012/ booksprints-fast-track-torigorous-open-educationalresources/

Thoms, J . J ., \& Thoms, B. L. (2014). Open educational resources in the United States: Insights from university foreign language directors. System, 45, 138- 146.

http:// dx.doi.org/ 10.1016/j.system.2014.05.006

Warner, C., \& Dupuy, B. (2018). Moving toward multiliteracies in foreign language teaching: Past and present perspectives. . and beyond. Foreign Language Annals, 51, 116- 128. https:// doi.org/ 10.1111/ flan.12316

Zapata, G. C. (2017). OER Materials for L2 Spanish teaching: Performance-based activities for novice and intermediate L2 Spanish students. Retrieved from https:/ / www.gzapatatexasam.com/ opensource-pedagogical-material

Zennaro, M., Canessa, E., Fonda, C., Belcher, M., \&Flickenger, R. (2007). Book sprint: A new model for rapid book authoring and content development. International J ournal of the Book, 4(1), 105109. Retrieved from http:// users.ictp.it/ mzennaro/ BookSprint.pdf 


\section{Appendix}

\section{Survey Questions}

1. What were your expectations before the book sprint?

2. What was your actual experience like? Was it similar or different to your expectations? Please explain.

3. How useful was your previous experience as a teacher when developing activities? Please explain.

4. How useful was your previous methodology training when developing activities? Please explain.

5. What were the most positive aspects of this experience?

6. What were the challenges you encountered when participating in the book sprint? How did you overcome them?

7. What resources did you use to complete the tasks assigned to you?

8. What is your perception of your final product? To what extent did your original idea change during the process?

9. What did you learn from this experience at the personal and professional levels?

10. What makes books sprints a worthwhile activity? 
${ }^{1}$ Rossomondo (2012) describes an OER materials-development project that involved the participation of graduate students. However, it did not employ the book-sprint methodology.

2 Since most of the pairs did not finish the culture sections, these sections were not included in the assessment.

3 The work environment during the book sprint week was observed by the researcher.

\section{Athabasca}

University

(cC) (i) 